\section{Observation of Embryo Abortion Characteristics of Ziziphus jujuba Mill. 'Zhongqiusucui'}

\author{
Fengxia Shao, Sen Wang, Saiyang Zhang, and Juan Chen \\ Central South University of Forestry and Technology, Changsha 410004, \\ China; and Engineering and Technology Research Institute of Jujube \\ Industry in Southern China, Central South University of Forestry and \\ Technology, Changsha 410004, Hunan, China
}

\section{Can Feng \\ Changsha County Zaoli Agricultural Technology Co., Ltd, Changsha County 410000, Hunan, China}

Additional index words. anatomical characteristics, kernel content rate, seed abortion, Ziziphus jujuba Mill.

\begin{abstract}
The embryo abortion rate of Ziziphus jujuba Mill. 'Zhongqiusucui' is high, which hinders cross-breeding. Research to identify the causes of embryo abortion is urgently required. To determine the embryo abortion pattern and create a foundation for further research, the embryo abortion characteristics of $Z$. jujuba Mill. 'Zhongqiusucui' were observed during this study. The results indicated that $Z$. jujuba Mill. 'Zhongqiusucui' was a cultivar with a high embryo abortion rate. Furthermore, there were some differences in the embryo abortion rates of jujube fruits in different batches. There was no significant difference between the first and second batches of jujube fruits. Large jujube fruits had a relatively low embryo abortion rate. Small jujube fruits had a relatively low kernel content rate and high embryo abortion rate. Most of the jujube fruits contained a single kernel, and some contained double kernels. The third batch of jujube fruits differed greatly from the first and second batches. The third batch had the highest degree of embryo abortion and all contained kernels were single. The embryo abortion degree of jujube fruits on the lignified bearing shoot was higher than that on the nonlignified bearing shoot, and the probability of jujube fruit with double kernels on the nonlignified bearing shoot was higher than that of the fruit on the lignified bearing shoot. The embryo abortion rates of jujube fruits with a smaller fruit shape index and larger fruit shape index were lower, and that of the medium (fruit shape index range, 1.30-1.60) was higher. The embryo abortion rates of globose, oblong globose, and long cylinder jujube fruits were lower, whereas that of cylindrical fruits was higher. Cracked jujube fruits did not contain normal seed kernels and their embryo abortion rate was $100 \%$.
\end{abstract}

Chinese jujube (Ziziphus jujuba Mill.), which belongs to the Rhamnaceae family, is one of the most economically important fruit trees in China (Qu and Wang, 1993). Its fruit has high nutritional and medicinal value because it contains several biologically active components required by the human body, including vitamin C, phenolics, flavonoids, triterpenic acids, polysaccharides, and microelements (Gao et al., 2013; Liu et al., 2015). In addition to its high economic value, Chinese jujube provides ecological benefits. Because of its ability to grow in diverse environments, the jujube tree has had a critical role in the adjustment of agricultural industrial structure and in the economic development of poverty-stricken regions of China. The improvement of jujube cultivars is essential to enhancing the quality, yield, and efficiency of jujube cultivation (Liu et al., 2014). Crossbreeding has been the primary means by which jujube trees have been bred to date, and this method is likely to continue to be useful in the future (Liu et al., 2014). However, embryo challenge of breeding new cultivar and improving the jujube industry.

Previous studies of embryo abortion of jujube have mainly focused on physiological and biochemical mechanisms and embryological observation, such as pollination biology (Liu et al., 2006; Wang, 2008), embryo development (Shao et al., 2020; Zhang et al., 2004), embryo abortion dynamics of different cultivars (Li et al., 2016), and changes in endogenous hormones that reduce sugar, total sugar, and minerals during embryo abortion (Wang et al., 2008). Although there have been some reports of the kernel content of jujube fruit (Gao et al., 2019), few studies have focused on the external characteristics of embryo abortion of jujube fruits. Moreover, the embryo development process and embryo abortion period of different jujube cultivars are different. Therefore, in this study, the natural embryo development of Z. jujuba Mill. 'Zhongqiusucui' was dynamically investigated and qualitatively graded to determine the overall trend and external development characteristics of embryo abortion, thereby creating a foundation for further study of the embryo abortion mechanism. The investigation of the embryo abortion status of Z. jujuba Mill. 'Zhongqiusucui' was used as the basis for its cross-breeding and had great significance.

\section{Materials and Methods}

Overview of the experimental site. The experimental site was the jujube tree experimental base of Central South University of Forestry and Technology (Qidong County, Hunan Province; lat. $26.78^{\circ} \mathrm{N}$, long. $112.12^{\circ} \mathrm{E}$ ). The area has a subtropical climate, with cold winters, hot and humid summers, abundant and unstable heat, and abundant rainfall with uneven seasonal distribution. The total area of the experimental field is $\approx 3335 \mathrm{~m}^{2}$, which is a rectangular distribution. The planting spacing of jujube trees was $2 \mathrm{~m} \times 3 \mathrm{~m}$, and the total number was 550.

Experimental cultivars. Five-year-old $Z$. abortion is a common phenomenon in jujube that prevents the formation of viable seeds and restricts cross-breeding efficiency; therefore, obtaining hybrid progeny remains a major challenge. To breed new cultivars and improve the jujube industry, an understanding of the causes of embryo abortion is urgent. Ziziphus jujuba Mill. 'Zhongqiusucui' is a new cultivar bred in Hunan Province. This fruit tree has many advantages, such as a high yield, high sugar content, rich flavor, good texture, strong adaptability, easy storability, and easy transportability (Wang et al., 2009); therefore, it has become the main cultivar for fresh consumption in southern China. However, Z. jujuba Mill. 'Zhongqiusucui' has disadvantages, such as severe abscission of flowers and fruits and easy fruit cracking; therefore, cross-breeding is required to acquire advantages from other jujube cultivars. However, cross-breeding also introduces certain issues, such as embryo abortion and nonsetting fruit. Research to identify the causes of embryo abortion is necessary to solve this jujuba Mill. 'Zhongqiusucui' trees that had been transplanted once were used for this study. We selected trees with good growth and developmental conditions, relatively uniform tree vigor, and no disease or pests.

Experimental methods. In the experimental field, 15 jujube trees with consistent growth were selected as the investigation objects according to the random sampling method of ' $S$ ' shape in July, August, and September. Four jujube bearing shoots of each selected tree were randomly chosen from the east, south, west, and north directions, and three to five jujube fruits of different sizes were randomly collected from each bearing shoot as the research objects. At the cracking stage of jujube fruits, $\approx 300$ jujube fruits with different cracking degrees were randomly collected from lignified and nonlignified bearing shoots. A vernier caliper was used to measure the vertical length and cross diameter of jujube fruit, and the shape index of each fruit was calculated. Then, the 
jujube fruit was dissected and observed, the number of kernels in each fruit was recorded, and the kernel rate was counted.

The vertical length of jujube fruit was measured as the maximum distance from the top to the shoulder of jujube fruit (Liu and Wang, 2009), as shown in Fig. 1. The cross diameter of jujube fruit was measured as the length of the widest section of jujube fruit (Liu and Wang, 2009), as shown in Fig. 1. The fruit shape index was measured as the ratio of the vertical length to the cross diameter of fruit (Liu and Wang, 2009). The shapes of jujube fruit with different fruit shape indexes are described in Fig. 2. The kernel content rate was measured as the percentage of the number of fruits with kernels in the total number of fruits (Liu and Wang, 2009). The embryo abortion rate was measured as (1 the number of fruits with kernels/investigated fruits) $\times 100 \%$ (Liang, 2013).

Data processing and analysis. Excel 2016 (Microsoft, Redmond, WA) was used for basic data statistics. SPSS 19.0 (IBM, Chicago, IL) was used for significance analysis and correlation analysis. Origin 9.0 (Origin, Northampton, MA) was used for mapping.

\section{Results and Analysis}

Anatomical characteristics of jujube fruits with embryo abortion. The jujube fruits were classified according to the vertical length. The morphological characteristics of the appearance of aborted fruit with aborted embryos with different vertical lengths are shown in Fig. 3. The well-developed seed became larger with fruit development, filling the whole ovary ventricle (Fig. 3A2-H2). During the development of jujube fruit, most of the fruits could not form normal kernels, and the appearance showed that their ovules stopped developing. As the early stage of ovule development stopped, the color was green (Fig. $3 \mathrm{~A} 3, \mathrm{~A} 4, \mathrm{~B} 3$, and B4). With the progress of fruit development, the color of ovules changed from green to light yellowish brown, and then from light yellowish brown to

Received for publication 8 Feb. 2021. Accepted for publication 16 Mar. 2021.

Published online 30 April 2021.

The key research and development project of $\mathrm{Hu}-$ nan Province 'Research and Demonstration of Technology for Improving Quality, Increasing Yield and High Value Utilization of Woody Grain Tree Species in Hunan Province (2018NK2043)', and the Postgraduate Science and Technology Innovation Fund Project of Central South University of Forestry Science and Technology 'Research on Embryo Abortion Mechanism of Fresh-eating Jujube in South China (CX2016A02)' provided financial support for the conduct of the research and preparation of this article. We thank Saiyang Zhang, Juan Chen, and Can Feng for assistance with the experiments, and Professor Sen Wang for valuable discussions.

S.W. is the corresponding author. E-mail: csuftwangsen@163.com.

This is an open access article distributed under the CC BY-NC-ND license (https://creativecommons. org/licenses/by-nc-nd/4.0/). yellowish brown or black. At the same time, the ovules shrank and the volume decreased continuously. At the hard stone stage, the kernels either disappeared or left tiny traces of kernels (Fig. 3C3-G3 and C4-G4). Kernels were able to form in some jujube fruits; however, in the later stage of fruit development, the kernels were browning and shriveling (Fig. $3 \mathrm{H} 3$ and H4). In the normal and completely fertile jujube fruit, the two ventricles of the ovary were filled by two seeds that enlarged as the fruit grew (Fig. 3B2). In the completely aborted jujube fruits, the two ventricles of the ovary were hollow after the kernels stopped developing early, and the two hollow ventricles were symmetrical in most cases (Fig. 3E4, F4, and G4). The development process of the two ventricles of the jujube fruit chamber containing only one normal kernel (incomplete abortion) was different with the advancement of time. The ventricle containing the normal kernel grew together with the seed, whereas the ventricle containing the abortive kernel was squeezed by the other ventricle over time and its space became increasingly smaller (Fig. 3E2, F2, and G2).

Abortion characteristics of jujube fruit embryos in different batches. There is a phenomenon in which fruit trees bear fruits more than once during a year; that is, the fruit trees can blossom and bear fruits many times during a year. Under the influence of natural environment or genetic characteristics, most fruit trees could only conduct flower bud differentiation and fruiting once per year, but there were still a few fruit trees flowering and fruiting two or more times (Zhou, 1999). Z. jujuba Mill. 'Zhongqiusucui' has the significant characteristic of three batches of fruiting every year (Hu, 2017; $\mathrm{Hu}$ et al., 2017). Fruits mainly grew on the bearing shoots of jujube stocks or the base of jujube heads of the first batch, those of the second batch mainly bore on the bearing shoots of the secondary branches of the middle and upper parts of the jujube heads, and jujube fruit setting of the third batch was mainly on the bearing shoots of the secondary branch or the extended branch of lignified jujube shoot (Hu et al., 2017). The jujube fruits of the first batch were dominant in cross-diameter and stalk length, whereas the jujube fruits of the second batch had the larger vertical length, fruit shape index, and ratio of edibility; the yield of the second batch was the highest (Hu, 2017). To further study the embryo abortion characteristics of $Z$. jujuba Mill. 'Zhongqiusucui', jujube fruits in different batches were collected and classified according to their vertical length, and the embryo abortion rate was statistically analyzed.

The embryo abortion rate of jujube fruits of the first batch is shown in Table 1. There were significant differences in the embryo abortion rate of jujube fruit of different sizes. The embryo abortion rate was highest $(98.79 \%)$ when the fruit vertical length ranged from 0.80 to $1.00 \mathrm{~cm}$ and the kernels contained in the fruits were single. The embryo abortion rate of jujube fruit with vertical lengths greater than $2.5 \mathrm{~cm}$ was lowest (93.26\%), and some fruits contained two kernels. Although the fruits with vertical lengths ranging from 1.21 to $1.40 \mathrm{~cm}$ had a lower kernel content rate $(2.86 \%)$, some of them had two kernels. In general, the kernel content rate of jujube fruits in the first batch was low. Overall, most of the kernels contained were single; only a few were double. The kernel content rate of large jujube fruits (vertical length range of $2.01-2.50 \mathrm{~cm}$ and vertical length $>2.50 \mathrm{~cm}$ ) was relatively higher. The kernel content rates of small jujube fruits

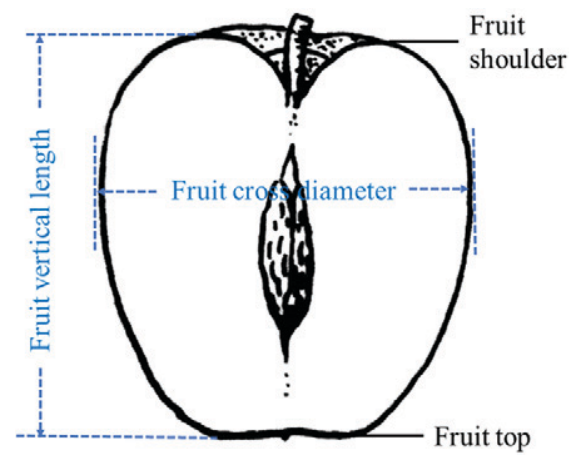

Fig. 1. Diagram of the vertical length and cross diameter measurement methods used for jujube fruits (Liu and Wang, 2009).

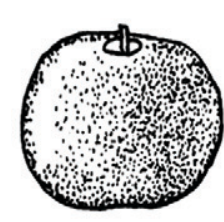

A. oblate

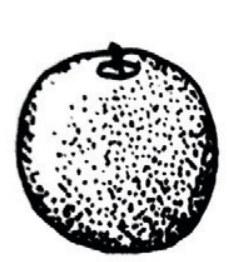

B. globose

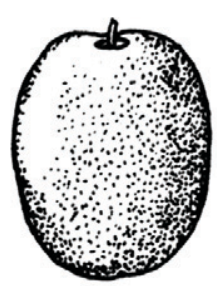

C. oblong globose

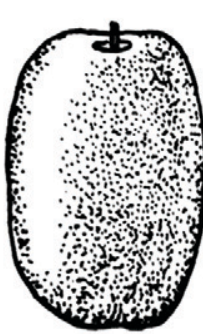

D. cylinder

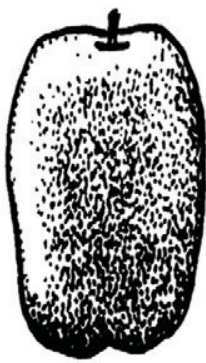

E. long cylinder

Fig. 2. Jujube fruit shape (Liu and Wang, 2009). The shape of jujube fruit with fruit shape index values $<0.90$ is oblate. The shape of jujube fruit with fruit shape index values of 0.90 to 1.10 is globose or nearly globose. The shape of jujube fruit with fruit shape index values of 1.10 to 1.30 is oblong globose. The shape of jujube fruit with fruit shape index values of 1.30 to 1.60 is cylindrical. The shape of jujube fruit with fruit shape index values $>1.60$ is long and cylindrical. 

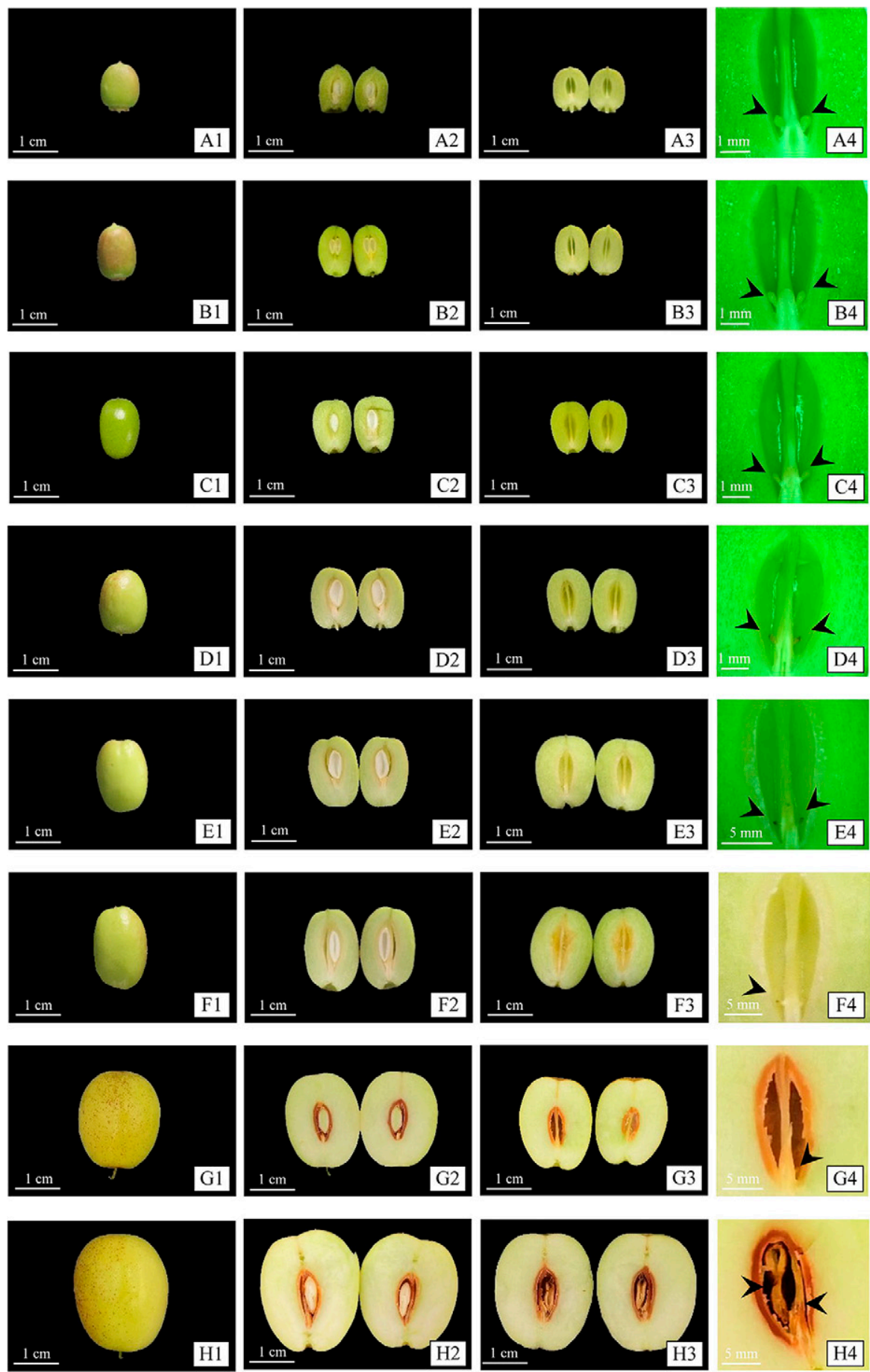

Fig. 3. Comparison of jujube fruits containing kernels and abortive jujube fruits of different sizes. (A) Jujube fruit with a vertical length of $1.0 \mathrm{~cm}$ and its anatomical characteristics: appearance of the fruit (A1); longitudinal section of the fruit with a single kernel (A2); longitudinal section of the embryo of the abortive fruit (A3); and longitudinal section of the ovary of the abortive fruit (A4) (arrows indicate the abortive ovules). (B) Fruit with a vertical length of $1.2 \mathrm{~cm}$ and its anatomical characteristics: appearance of the fruit (B1); longitudinal section of the fruit with two normal kernels (B2); longitudinal section of the embryo of the abortive fruit (B3); and longitudinal section of the ovary of the abortive fruit (B4) (arrows show the abortive ovules). (C) Jujube fruit with a vertical length of $1.4 \mathrm{~cm}$ and its anatomical characteristics: appearance of the fruit $(\mathbf{C 1})$; longitudinal section of the fruit with a single kernel (C2); longitudinal section of the abortive fruit (C3); and longitudinal section of the ovary of the abortive fruit (C4) (arrows indicate abortive ovules). (D) The jujube fruit with a vertical length of $1.6 \mathrm{~cm}$ and its anatomical characteristics: appearance of the fruit (D1); longitudinal section of the fruit with a single kernel (D2); longitudinal section of the embryo of the abortive fruit (D3); and longitudinal section of the ovary of the abortive fruit (D4) (arrows indicate abortive ovules). (E) Jujube fruit with a vertical length of $1.8 \mathrm{~cm}$ and its anatomical characteristics: appearance of the fruit (E1); longitudinal section of the fruit with a single kernel (E2); longitudinal section of the abortive fruit (E3); and longitudinal section of the ovary of the abortive fruit (E4) (arrows indicate abortive ovules). (F) Jujube fruit with a vertical length of $2.0 \mathrm{~cm}$ and its anatomical characteristics: appearance of the fruit (F1); longitudinal section of the fruit with a single kernel (F2); longitudinal section of the abortive fruit (F3); and longitudinal section of the ovary of the abortive fruit (F4) (arrow indicates abortive ovule). (G) Jujube fruit with a vertical length of $2.5 \mathrm{~cm}$ and its anatomical characteristics: appearance of the fruit (G1); longitudinal section of the fruit with a single kernel (G2); longitudinal section of the abortive fruit (G3); and longitudinal section of the ovary of the abortive fruit (G4) (arrow indicates abortive ovule). (H) Jujube fruit with a vertical length of $3.0 \mathrm{~cm}$ and its anatomical characteristics: appearance of the fruit (H1); longitudinal section of the fruit with a single kernel (H2); longitudinal section of the abortive fruit (H3); and longitudinal section of the ovary of the abortive fruit (H4) (arrows point to the abortive kernel and the narrow ovary). 
(vertical length range, $0.80-1.00 \mathrm{~cm}$ ) and medium jujube fruit (vertical length range, $1.41-1.60 \mathrm{~cm}$ ) were relatively lower.

As shown in Table 2, the embryo abortion rate of jujube fruits of different sizes in the second batch differed significantly. The kernel content rate of jujube fruits with a vertical length ranging from 0.80 to $1.00 \mathrm{~cm}$ was the lowest $(1.12 \%)$; their embryo abortion rate was as high as $98.88 \%$ and all the kernels contained were single. The jujube fruits with a vertical length of 1.01 to $1.20 \mathrm{~cm}$ had the second highest kernel content rate and an embryo abortion rate of was $98.15 \%$; the kernels contained were all single. The jujube fruits with a vertical length ranging from 2.01 to 2.50 $\mathrm{cm}$ had a kernel content rate of $7.35 \%$, and some of them contained two kernels. The kernel content rate of fruits with vertical lengths greater than $2.50 \mathrm{~cm}$ was highest $(13.46 \%)$, and their embryo abortion rate was lowest $(86.54 \%)$. Although the percentage of kernels in fruits with vertical lengths of 1.21 to $1.40 \mathrm{~cm}$ was low, some of them contained double kernels (1.47\%). The kernel content rate of jujube fruits with several other grades were similar and low; moreover, all the contained seeds were single. Overall, the kernel content rate of jujube fruit in the second batch was low. Most of the seeds contained in jujube fruits were single, and a few jujube fruits contained double kernels. The embryo abortion rate of large fruits (vertical length $>2.00 \mathrm{~cm}$ ) was low, and the embryo abortion rate of small fruits (vertical length range, $0.80-1.20 \mathrm{~cm}$ ) was higher.

As shown in Table 3, the embryo abortion rate of jujube fruits with different fruit sizes in the third batch was significantly different. The kernel content rates of jujube fruits with vertical lengths of 1.01 to $1.20 \mathrm{~cm}$ and $>2.50 \mathrm{~cm}$ were the lowest $(0.00 \%)$, and the embryo abortion rate was as high as $100 \%$. The embryo abortion rate of jujube fruits with a vertical length of 1.81 to $1.00 \mathrm{~cm}$ was lowest $(91.89 \%)$. There were no significant differences in the kernel content rates and embryo abortion rates among fruits with other grades, and the embryo abortion rates were high. In the third batch, the kernel content rates were low, and all contained kernels were single. No jujube fruits containing double kernels were found. The kernel content rates of larger fruits (with vertical lengths $>2.50 \mathrm{~cm}$ ) and smaller fruits (vertical length range, $0.80-1.20 \mathrm{~cm}$ ) were relatively lower. The kernel content rates of medium and large jujube fruits (vertical length, 1.81-2.00 $\mathrm{cm}$ ) were relatively higher.

The embryo abortion situations of three batches of jujube fruits were compared (Fig. 4). There were some differences in embryo abortion among the three batches. Overall, the embryo abortion situations of fruits in the first batch and second batch were similar, whereas the embryo abortion situation of the third batch was significantly different from that of the first and second batches. In terms of the degree of abortion, the embryo abortion rate of fruits in the third batch was higher than those of the first and second batches. The fruits with higher embryo abortion rates were larger and smaller fruits, whereas the jujube fruits with higher kernel content rates were medium fruits. However, compared with the third batch, the jujube fruits of the first and second batches had relatively lower embryo abortion rates, and the small fruits had higher embryo abortion rates.

Table 1. Embryo abortion rate of jujube fruits in the first batch.

\begin{tabular}{|c|c|c|c|c|c|c|c|}
\hline $\begin{array}{l}\text { Fruit vertical } \\
\text { length }(\mathrm{cm})\end{array}$ & $\begin{array}{l}\text { Fruit cross diam } \\
(\mathrm{cm})\end{array}$ & Fruit wt $(\mathrm{g})$ & Fruit shape index & $\begin{array}{l}\text { Ratio of double } \\
\text { kernels }(\%)\end{array}$ & $\begin{array}{l}\text { Ratio of single } \\
\text { kernels }(\%)\end{array}$ & $\begin{array}{c}\text { Ratio of kernels } \\
(\%)\end{array}$ & $\begin{array}{c}\text { Embryo abortion } \\
\text { rate }(\%)\end{array}$ \\
\hline $1.01-1.20$ & $0.62-0.93$ & $0.25-0.53$ & $1.20-1.53$ & $0.00 \pm 0.00 \mathrm{~b}$ & $4.76 \pm 1.48 \mathrm{c}$ & $4.76 \pm 1.48 \mathrm{c}$ & $95.24 \pm 1.48 b$ \\
\hline $1.21-1.40$ & $0.79-1.11$ & $0.47-0.81$ & $1.32-1.60$ & $0.91 \pm 0.10 \mathrm{a}$ & $1.95 \pm 0.53 \mathrm{~d}$ & $2.86 \pm 0.59 \mathrm{~cd}$ & $97.14 \pm 0.59 \mathrm{ab}$ \\
\hline $1.61-1.80$ & $0.98-1.45$ & $0.97-1.99$ & $1.22-1.59$ & $0.00 \pm 0.00 \mathrm{~b}$ & $2.04 \pm 0.25 \mathrm{~d}$ & $2.04 \pm 0.25 \mathrm{~d}$ & $97.96 \pm 0.25 \mathrm{a}$ \\
\hline $1.81-2.00$ & $1.15-1.53$ & $1.25-2.71$ & $1.28-1.72$ & $0.00 \pm 0.00 \mathrm{~b}$ & $3.22 \pm 1.46 \mathrm{~cd}$ & $3.22 \pm 1.46 \mathrm{~cd}$ & $96.78 \pm 1.46 \mathrm{ab}$ \\
\hline $2.01-2.50$ & $1.34-2.45$ & $1.80-6.06$ & $1.00-1.72$ & $0.00 \pm 0.00 \mathrm{~b}$ & $6.74 \pm 0.88 \mathrm{~b}$ & $6.74 \pm 0.88 \mathrm{~b}$ & $93.26 \pm 0.88 \mathrm{c}$ \\
\hline
\end{tabular}

The Duncan analysis method was used. Different lowercase letters in the same column indicate significant differences at the $5 \%$ level $(P<0.05)$.

Table 2. Embryo abortion rate of jujube fruits in the second batch.

\begin{tabular}{|c|c|c|c|c|c|c|c|}
\hline $\begin{array}{l}\text { Fruit vertical } \\
\text { length }(\mathrm{cm})\end{array}$ & $\begin{array}{l}\text { Fruit cross diam } \\
(\mathrm{cm})\end{array}$ & Fruit wt (g) & Fruit shape index & $\begin{array}{l}\text { Ratio of double } \\
\text { kernels }(\%)\end{array}$ & $\begin{array}{c}\text { Ratio of single } \\
\text { kernels }(\%)\end{array}$ & $\begin{array}{c}\text { Ratio of kernels } \\
(\%)\end{array}$ & $\begin{array}{c}\text { Embryo abortion } \\
\text { rate }(\%)\end{array}$ \\
\hline $0.80-1.00$ & $0.50-0.80$ & $0.13-0.50$ & $1.28-1.75$ & $0.00 \pm 0.00 \mathrm{~b}$ & $1.12 \pm 1.08 \mathrm{c}$ & $1.12 \pm 1.08 \mathrm{c}$ & $98.88 \pm 1.08 \mathrm{a}$ \\
\hline $1.01-1.20$ & $0.61-0.90$ & $0.20-0.62$ & $1.25-1.66$ & $0.00 \pm 0.00 \mathrm{~b}$ & $1.85 \pm 1.19 \mathrm{c}$ & $1.85 \pm 1.19 \mathrm{c}$ & $98.15 \pm 1.19 \mathrm{a}$ \\
\hline $1.21-1.40$ & $0.75-1.22$ & $0.34-1.35$ & $1.07-1.75$ & $0.00 \pm 0.00 \mathrm{~b}$ & $1.96 \pm 1.23 \mathrm{c}$ & $1.96 \pm 1.23 \mathrm{c}$ & $98.04 \pm 1.23 \mathrm{a}$ \\
\hline $1.41-1.60$ & $0.85-1.29$ & $0.78-1.29$ & $1.22-1.66$ & $0.00 \pm 0.00 \mathrm{~b}$ & $1.79 \pm 1.78 \mathrm{c}$ & $1.79 \pm 1.78 \mathrm{c}$ & $98.21 \pm 1.78 \mathrm{a}$ \\
\hline $1.61-1.80$ & $1.08-1.48$ & $0.97-1.72$ & $1.29-1.60$ & $0.00 \pm 0.00 \mathrm{~b}$ & $2.56 \pm 0.92 \mathrm{c}$ & $2.56 \pm 0.92 \mathrm{c}$ & $97.44 \pm 0.92 \mathrm{a}$ \\
\hline $1.81-2.00$ & $1.09-1.40$ & $1.07-2.22$ & $1.20-1.67$ & $0.00 \pm 0.00 \mathrm{~b}$ & $2.63 \pm 0.80 \mathrm{c}$ & $2.63 \pm 0.80 \mathrm{c}$ & $97.37 \pm 0.80 \mathrm{a}$ \\
\hline $2.01-2.50$ & $1.40-2.18$ & $1.68-6.12$ & $1.09-1.68$ & $1.47 \pm 0.74 \mathrm{a}$ & $5.88 \pm 0.59 b$ & $5.88 \pm 0.77 b$ & $92.65 \pm 0.77 b$ \\
\hline$>2.50$ & $1.88-2.56$ & $4.06-9.41$ & $1.11-1.35$ & $0.00 \pm 0.00 \mathrm{~b}$ & $13.46 \pm 0.75 \mathrm{a}$ & $13.46 \pm 0.75 \mathrm{a}$ & $86.54 \pm 0.75 c$ \\
\hline
\end{tabular}

The Duncan analysis method was used. Different lowercase letters in the same column indicate significant differences at the $5 \%$ level $(P<0.05)$.

Table 3. Embryo abortion rate of jujube fruits in the third batch.

\begin{tabular}{lccccccc}
\hline $\begin{array}{l}\text { Fruit vertical } \\
\text { length }(\mathrm{cm})\end{array}$ & $\begin{array}{c}\text { Fruit cross diam } \\
(\mathrm{cm})\end{array}$ & Fruit wt $(\mathrm{g})$ & Fruit shape index & $\begin{array}{c}\text { Ratio of double } \\
\text { kernels }(\%)\end{array}$ & $\begin{array}{c}\text { Ratio of single } \\
\text { kernels }(\%)\end{array}$ & $\begin{array}{c}\text { Ratio of kernels } \\
(\%)\end{array}$ & $\begin{array}{c}\text { Embryo abortion } \\
\text { rate }(\%)\end{array}$ \\
\hline $0.80-1.00$ & $0.62-0.70$ & $0.23-0.28$ & $1.32-1.48$ & 0.00 & $0.92 \pm 0.81 \mathrm{bc}$ & $0.92 \pm 0.81 \mathrm{bc}$ & $99.08 \pm 0.81 \mathrm{ab}$ \\
$1.01-1.20$ & $0.68-0.92$ & $0.29-0.56$ & $1.28-1.69$ & 0.00 & $0.00 \pm 0.00 \mathrm{c}$ & $0.00 \pm 0.00 \mathrm{c}$ & $100 \pm 0.00 \mathrm{a}$ \\
$1.21-1.40$ & $0.80-1.12$ & $0.57-0.96$ & $1.18-1.57$ & 0.00 & $1.79 \pm 0.80 \mathrm{~b}$ & $1.79 \pm 0.80 \mathrm{~b}$ & $98.21 \pm 0.80 \mathrm{~b}$ \\
$1.41-1.60$ & $0.90-1.25$ & $0.60-1.23$ & $1.25-1.65$ & 0.00 & $2.05 \pm 0.40 \mathrm{~b}$ & $2.05 \pm 0.40 \mathrm{~b}$ & $97.95 \pm 0.40 \mathrm{~b}$ \\
$1.61-1.80$ & $0.98-1.36$ & $0.74-2.06$ & $1.15-1.74$ & 0.00 & $1.72 \pm 0.56 \mathrm{~b}$ & $1.72 \pm 0.56 \mathrm{~b}$ & $98.28 \pm 0.56 \mathrm{~b}$ \\
$1.81-2.00$ & $1.10-1.70$ & $0.74-3.63$ & $1.24-1.73$ & 0.00 & $8.11 \pm 1.08 \mathrm{a}$ & $8.11 \pm 1.08 \mathrm{a}$ & $91.89 \pm 1.08 \mathrm{c}$ \\
$2.01-2.50$ & $1.15-2.11$ & $2.63-5.77$ & $1.15-1.74$ & 0.00 & $1.82 \pm 0.11 \mathrm{~b}$ & $1.82 \pm 0.11 \mathrm{~b}$ & $98.18 \pm 0.11 \mathrm{~b}$ \\
$>2.50$ & $1.84-2.38$ & $3.83-9.21$ & $1.06-1.45$ & 0.00 & $0.00 \pm 0.00 \mathrm{c}$ & $0.00 \pm 0.00 \mathrm{c}$ & $100 \pm 0.00 \mathrm{a}$ \\
\hline
\end{tabular}

The Duncan analysis method was used. Different lowercase letters in the same column indicate significant differences at the $5 \%$ level $(P<0.05)$. 


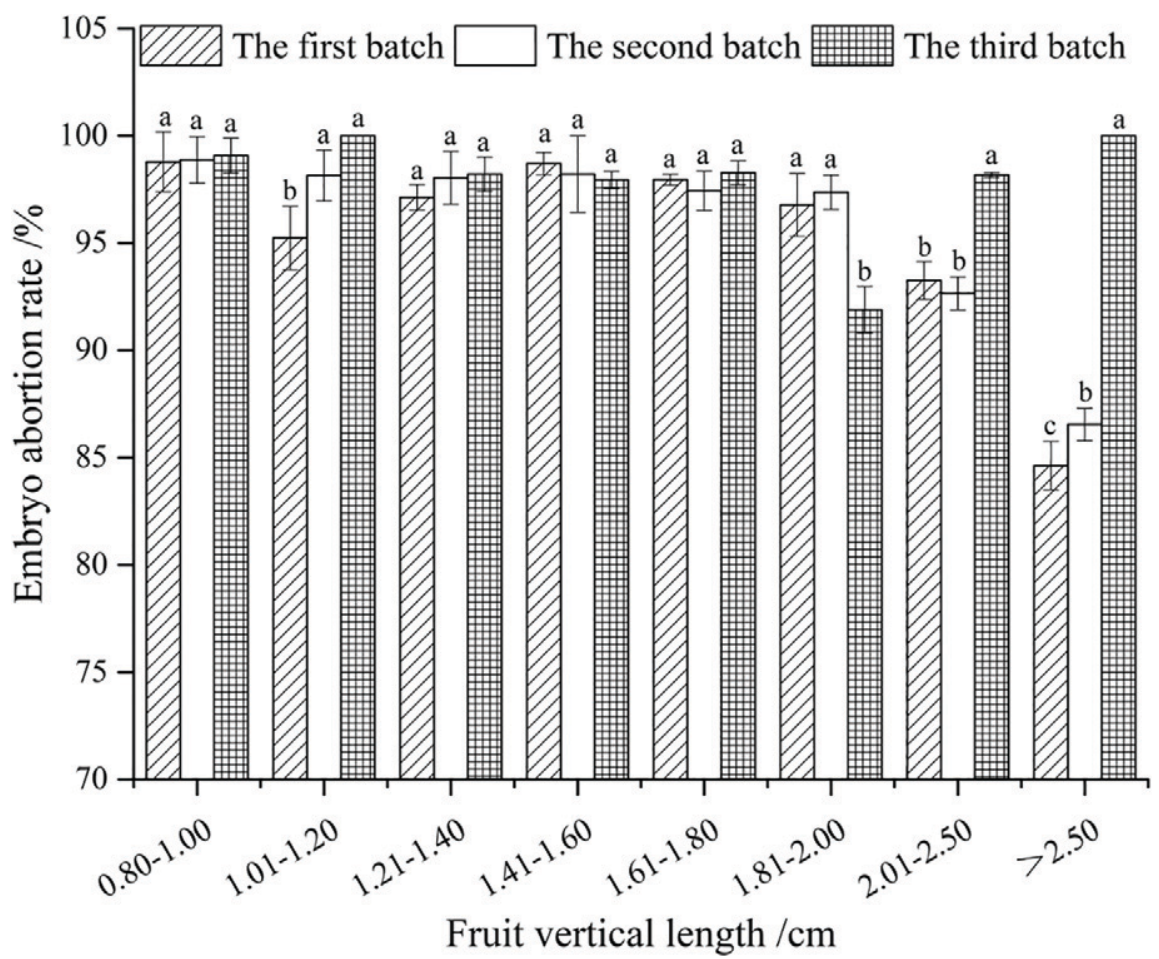

Fig. 4. Comparison of embryo abortion rates of jujube fruits of different batches. The Duncan analysis method was used. Different lowercase letters in the same fruit vertical length range indicate significant differences among different batches at the 5\% level $(P<0.05)$.

Regarding the seeds contained, all the kernels contained in the jujube fruits of the third batch were single; however, double kernels were found in some fruits of the first and second batches of jujube fruits, although the double kernel rate was low.

Embryo abortion characteristics of jujube fruits on two types of bearing shoots. There are two types of bearing shoots for fresh jujube in southern China, namely, the lignified bearing shoot and nonlignified bearing shoot (Yan et al., 2013; Wang and Yan, 2014; Wang high as $99.31 \%$. All the contained seeds were single. Jujube fruits with vertical lengths of 1.01 to $1.20 \mathrm{~cm}$ had the second highest kernel content rate and an abortion rate of $99.24 \%$; all the kernels contained were single. The kernel content rate of fruits with vertical lengths greater than $2.5 \mathrm{~cm}$ was highest $(8.82 \%)$; all contained seeds were single. Jujube fruits with vertical lengths of 2.01 to $2.50 \mathrm{~cm}$ had the second highest kernel content rate $(4.13 \%)$, and some fruits contained double kernels. In general, the kernel content rate of the jujube fruits on the lignified bearing shoot was low. Most contained kernels were single, but a few were double. The kernel content rate of large fruits (vertical length $>2.00 \mathrm{~cm}$ ) was relatively higher. The kernel content rate of small fruits (vertical length range, $0.80-1.20 \mathrm{~cm}$ ) was lower.

As shown in Table 5, there were significant differences in the embryo abortion rates of jujube fruits of different sizes on nonlignified bearing shoots. The kernel content rate of fruits with vertical lengths of 0.80 to 1.00 $\mathrm{cm}$ was the lowest $(0.93 \%)$, and the embryo abortion rate was as high as $99.07 \%$; all kernels were single. Jujube fruits with vertical lengths ranging from $1.21 \mathrm{~cm}$ to $1.40 \mathrm{~cm}$ had the second highest kernel content rate, and their embryo abortion rate was $99.05 \%$; all seeds were double. The kernel content rate of jujube fruits with vertical lengths greater than $2.50 \mathrm{~cm}$ was the highest (16.67\%), and their embryo abortion rate was the lowest, $83.33 \%$; some kernels contained were double. Jujube fruits with a vertical length of 2.01 to $2.50 \mathrm{~cm}$ had the second highest kernel content rate $(6.59 \%)$. There was no significant difference in kernel content rates among jujube fruits of other grades; the embryo abortion rates of jujube fruits of other grades were higher and the kernels contained in these fruits were all single. Overall, the kernel content rate of jujube fruits on

Table 4. Embryo abortion rate of jujube fruits on lignified bearing shoots.

\begin{tabular}{lccccccc}
\hline $\begin{array}{l}\text { Fruit vertical } \\
\text { length }(\mathrm{cm})\end{array}$ & $\begin{array}{c}\text { Fruit cross diam } \\
(\mathrm{cm})\end{array}$ & Fruit wt $(\mathrm{g})$ & Fruit shape index & $\begin{array}{c}\text { Ratio of double } \\
\text { kernels }(\%)\end{array}$ & $\begin{array}{c}\text { Ratio of single } \\
\text { kernels }(\%)\end{array}$ & $\begin{array}{c}\text { Ratio of kernels } \\
(\%)\end{array}$ & $\begin{array}{c}\text { Embryo abortion } \\
\text { rate }(\%)\end{array}$ \\
\hline $0.80-1.00$ & $0.50-0.80$ & $0.13-0.35$ & $1.25-1.64$ & $0.00 \pm 0.00 \mathrm{~b}$ & $0.69 \pm 0.55 \mathrm{~d}$ & $0.69 \pm 0.55 \mathrm{~d}$ & $99.31 \pm 0.55 \mathrm{a}$ \\
$1.01-1.20$ & $0.61-0.85$ & $0.20-0.56$ & $1.25-1.69$ & $0.00 \pm 0.00 \mathrm{~b}$ & $0.76 \pm 0.11 \mathrm{~d}$ & $0.76 \pm 0.12 \mathrm{~d}$ & $99.24 \pm 0.12 \mathrm{a}$ \\
$1.21-1.40$ & $0.81-1.10$ & $0.43-1.35$ & $1.20-1.76$ & $0.00 \pm 0.00 \mathrm{~b}$ & $1.12 \pm 0.17 \mathrm{~cd}$ & $1.12 \pm 0.17 \mathrm{~cd}$ & $98.88 \pm 0.17 \mathrm{ab}$ \\
$1.41-1.60$ & $0.82-1.25$ & $0.68-1.21$ & $1.28-1.64$ & $0.00 \pm 0.00 \mathrm{~b}$ & $1.06 \pm 1.00 \mathrm{~cd}$ & $1.06 \pm 1.00 \mathrm{~cd}$ & $98.94 \pm 1.00 \mathrm{ab}$ \\
$1.61-1.80$ & $1.02-1.38$ & $0.74-1.63$ & $1.23-1.65$ & $0.00 \pm 0.00 \mathrm{~b}$ & $1.97 \pm 0.08 \mathrm{c}$ & $1.97 \pm 0.08 \mathrm{c}$ & $98.03 \pm 0.08 \mathrm{~b}$ \\
$1.81-2.00$ & $1.10-1.69$ & $0.97-3.63$ & $1.14-1.65$ & $0.00 \pm 0.00 \mathrm{~b}$ & $3.28 \pm 0.93 \mathrm{~b}$ & $3.28 \pm 0.93 \mathrm{~b}$ & $96.72 \pm 0.93 \mathrm{c}$ \\
$2.01-2.50$ & $1.11-2.21$ & $1.69-5.77$ & $1.11-1.89$ & $0.83 \pm 0.15 \mathrm{a}$ & $3.30 \pm 0.16 \mathrm{~b}$ & $4.13 \pm 0.27 \mathrm{~b}$ & $95.87 \pm 0.27 \mathrm{c}$ \\
$>2.50$ & $2.02-2.78$ & $3.8-10.05$ & $1.05-1.34$ & $0.00 \pm 0.00 \mathrm{~b}$ & $8.82 \pm 0.55 \mathrm{a}$ & $8.82 \pm 0.55 \mathrm{a}$ & $91.18 \pm 0.55 \mathrm{~d}$ \\
\hline
\end{tabular}

The Duncan analysis method was used. Different lowercase letters in the same column indicate significant differences at the $5 \%$ level $(P<0.05)$.

Table 5. Embryo abortion rate of jujube fruits on nonlignified bearing shoots.

\begin{tabular}{|c|c|c|c|c|c|c|c|}
\hline $\begin{array}{l}\text { Fruit vertical } \\
\text { length }(\mathrm{cm})\end{array}$ & $\begin{array}{l}\text { Fruit cross diam } \\
(\mathrm{cm})\end{array}$ & Fruit wt (g) & Fruit shape index & $\begin{array}{l}\text { Ratio of double } \\
\text { kernels }(\%)\end{array}$ & $\begin{array}{c}\text { Ratio of single } \\
\text { kernels }(\%)\end{array}$ & $\begin{array}{c}\text { Ratio of kernels } \\
(\%)\end{array}$ & $\begin{array}{c}\text { Embryo abortion } \\
\text { rate }(\%)\end{array}$ \\
\hline$\overline{0.80-1.00}$ & $0.50-0.8$ & $0.12-0.36$ & $1.23-1.63$ & $0.00 \pm 0.00 \mathrm{c}$ & $0.93 \pm 0.10 \mathrm{~d}$ & $0.93 \pm 0.11 \mathrm{~d}$ & $99.07 \pm 0.11 \mathrm{a}$ \\
\hline $1.01-1.20$ & $0.78-0.92$ & $0.28-0.62$ & $1.18-1.48$ & $0.00 \pm 0.00 \mathrm{c}$ & $1.18 \pm 0.37 \mathrm{~d}$ & $1.18 \pm 0.37 \mathrm{~d}$ & $98.82 \pm 0.37 \mathrm{a}$ \\
\hline $1.21-1.40$ & $0.78-1.12$ & $0.44-1.70$ & $1.18-1.64$ & $0.95 \pm 0.23 \mathrm{~b}$ & $0.00 \pm 0.00 \mathrm{e}$ & $0.95 \pm 0.23 \mathrm{~d}$ & $99.05 \pm 0.23 \mathrm{a}$ \\
\hline $1.41-1.60$ & $0.89-1.22$ & $0.62-1.15$ & $1.21-1.74$ & $0.00 \pm 0.00 \mathrm{c}$ & $1.49 \pm 0.65 \mathrm{~d}$ & $1.49 \pm 0.65 \mathrm{~d}$ & $98.51 \pm 0.65 \mathrm{a}$ \\
\hline $1.61-1.80$ & $0.98-1.51$ & $0.96-2.06$ & $1.20-1.74$ & $0.00 \pm 0.00 \mathrm{c}$ & $1.03 \pm 0.12 \mathrm{~d}$ & $1.03 \pm 0.12 \mathrm{~d}$ & $98.97 \pm 0.12 \mathrm{a}$ \\
\hline $1.81-2.00$ & $1.10-1.62$ & $1.21-3.43$ & $1.21-1.65$ & $0.00 \pm 0.00 \mathrm{c}$ & $5.41 \pm 0.57 \mathrm{c}$ & $5.41 \pm 0.57 \mathrm{c}$ & $94.59 \pm 0.57 b$ \\
\hline $2.01-2.50$ & $1.25-2.45$ & $1.68-2.12$ & $1.10-1.61$ & $0.00 \pm 0.00 \mathrm{c}$ & $6.59 \pm 0.39 \mathrm{~b}$ & $6.59 \pm 0.39 b$ & $93.41 \pm 0.39 \mathrm{c}$ \\
\hline$>2.50$ & $1.86-2.45$ & $4.03-7.77$ & $1.04-1.45$ & $1.39 \pm 0.37 \mathrm{a}$ & $15.28 \pm 0.23 \mathrm{a}$ & $16.67 \pm 0.37 \mathrm{a}$ & $83.33 \pm 0.37 \mathrm{~d}$ \\
\hline
\end{tabular}

The Duncan analysis method was used. Different lowercase letters in the same column indicate significant differences at the $5 \%$ level $(P<0.05)$. 


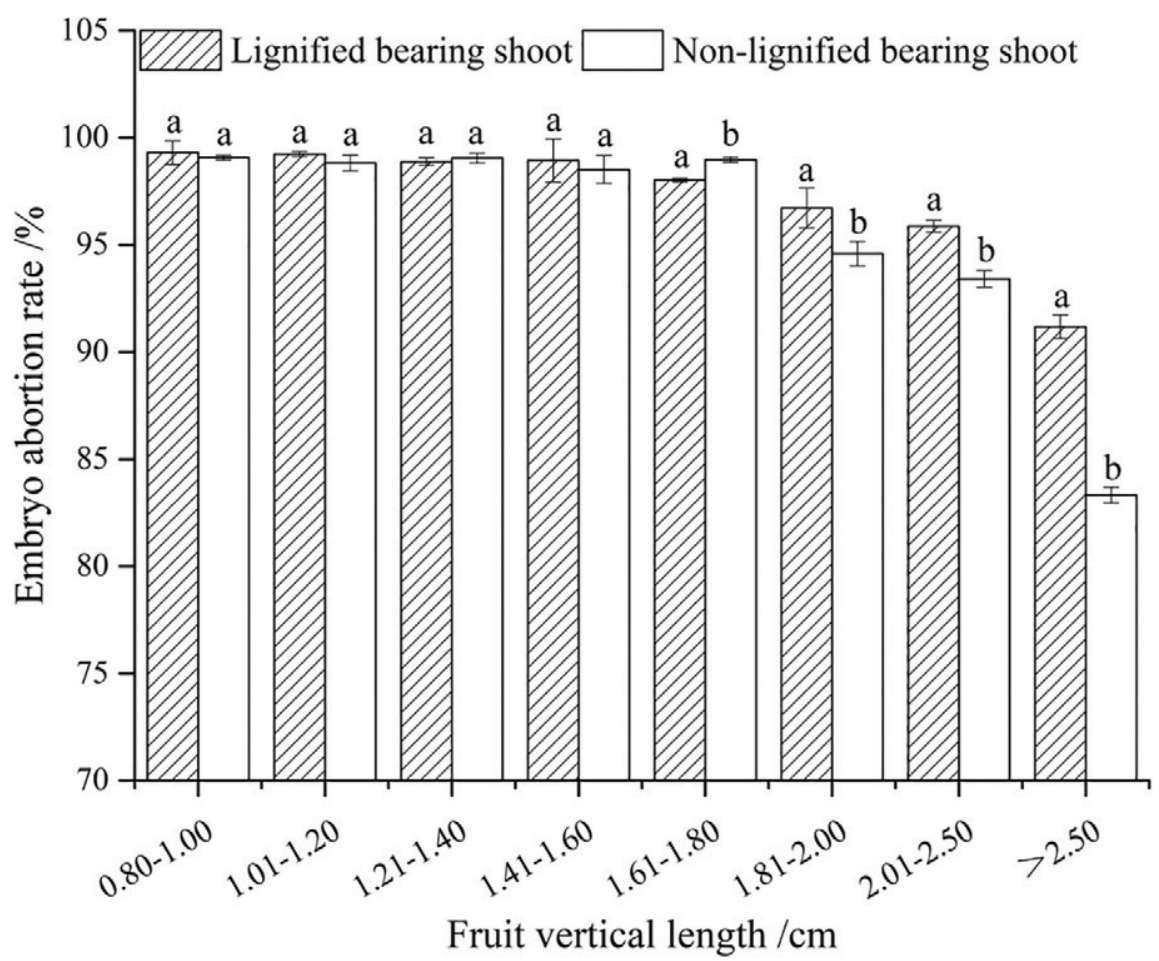

Fig. 5. Embryo abortion rates of jujube fruit on two types of bearing shoots. The Duncan analysis method was used. Different lowercase letters in the same fruit vertical length range indicate significant differences between different types of bearing shoots at the $5 \%$ level $(P<0.05)$.

Table 6. Embryo abortion rate of jujube fruits with different fruit shape index.

\begin{tabular}{lcccc}
\hline Fruit shape index & $\begin{array}{c}\text { Ratio of double } \\
\text { kernels (\%) }\end{array}$ & $\begin{array}{c}\text { Ratio of single kernels } \\
(\%)\end{array}$ & $\begin{array}{c}\text { Ratio of kernels } \\
(\%)\end{array}$ & $\begin{array}{c}\text { Embryo abortion rate } \\
(\%)\end{array}$ \\
\hline $1.00-1.10$ & $5.26 \pm 0.42 \mathrm{a}$ & $0.00 \pm 0.00 \mathrm{~b}$ & $5.26 \pm 0.42 \mathrm{~b}$ & $94.74 \pm 0.42 \mathrm{~b}$ \\
$1.11-1.20$ & $0.00 \pm 0.00 \mathrm{c}$ & $6.90 \pm 1.77 \mathrm{a}$ & $6.9 \pm 1.79 \mathrm{ab}$ & $93.1 \pm 1.79 \mathrm{bc}$ \\
$1.21-1.30$ & $0.47 \pm 0.07 \mathrm{~b}$ & $7.11 \pm 0.70 \mathrm{a}$ & $7.58 \pm 0.67 \mathrm{a}$ & $92.42 \pm 0.67 \mathrm{c}$ \\
$1.31-1.40$ & $0.00 \pm 0.00 \mathrm{c}$ & $0.69 \pm 0.31 \mathrm{~b}$ & $0.69 \pm 0.31 \mathrm{c}$ & $99.31 \pm 0.31 \mathrm{a}$ \\
$1.41-1.50$ & $0.00 \pm 0.00 \mathrm{c}$ & $1.33 \pm 0.45 \mathrm{~b}$ & $1.33 \pm 0.45 \mathrm{c}$ & $98.67 \pm 0.45 \mathrm{a}$ \\
$1.51-1.60$ & $0.00 \pm 0.00 \mathrm{c}$ & $1.31 \pm 0.65 \mathrm{~b}$ & $1.31 \pm 0.65 \mathrm{c}$ & $98.69 \pm 0.65 \mathrm{a}$ \\
$>1.60$ & $0.00 \pm 0.00 \mathrm{c}$ & $5.67 \pm 1.37 \mathrm{a}$ & $5.67 \pm 1.37 \mathrm{~b}$ & $94.33 \pm 1.37 \mathrm{~b}$ \\
\hline
\end{tabular}

The Duncan analysis method was used. Different lowercase letters in the same column indicate significant differences at the $5 \%$ level $(P<0.05)$.
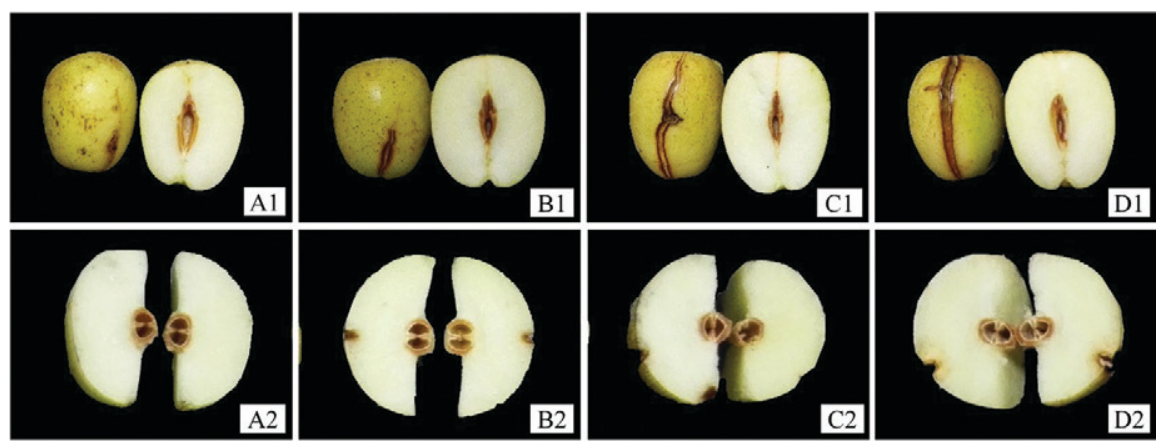

Fig. 6. Embryo abortion situation of cracked jujube fruits. (A) Longitudinal section (A1) and cross-section (A2) of slightly cracking jujube fruit. (B) Longitudinal section (B1) and cross-section (B2) of mildly cracking jujube fruit. (C) Longitudinal section (C1) and cross-section (C2) of moderately cracking jujube fruit. (D) Longitudinal section (D1) and cross-section (D2) of severely cracking jujube fruit.

nonlignified bearing shoots was low; the kernels of most jujube fruits containing seeds were single, and a small number of them contained double seeds. The kernel content rate of large fruits (vertical length $>2.00 \mathrm{~cm}$ ) was relatively higher. The kernel content rates of small fruits (vertical length range, 0.80-1.00 $\mathrm{cm}$ ) and medium fruits (vertical length range, $1.21-1.40 \mathrm{~cm}$ ) were relatively lower.

The embryo abortion situations of jujube fruits on two types of bearing shoots were compared (Fig. 5). Overall, the embryo abortion degree of fruits on lignified bearing shoots was higher than that of nonlignified bearing shoots. The probability of double kernels contained in jujube fruits on nonlignified bearing shoots was higher than that of jujube fruits on lignified bearing shoots. The higher kernel content rate of the two types of bearing shoots was found mainly for the large and medium fruits, and the lower kernel content and higher abortion rates were found mainly for small fruits.

Embryo abortion characteristics of jujube fruits with different fruit shape index values. The embryo abortion rates of jujube fruits with different fruit shape index values are shown in Table 6. There were significant differences in the embryo abortion rates among jujube fruits with different fruit shape index values. The embryo abortion rates of fruits with a smaller fruit shape index value (range, $1.00-1.30)$ or larger fruit shape index value $(>1.60)$ were lower, and that of intermediate fruits (fruit shape index range, 1.30-1.60) was higher. The shape of fruits with shape index values ranging from 1.00 to 1.30 was close to globose and oblong globose. The shape of fruits with shape index values greater than 1.60 was long and cylindrical. The shape of fruits with shape index values ranging from 1.31 to 1.60 was cylindrical (Fig. 2). The embryo abortion rates of fruits with globose, oblong globose, or long cylindrical shapes were lower, and that of cylindrical fruits was higher.

Embryo abortion characteristics of cracked jujube fruits. At the cracking stage of jujube fruits, $\approx 300$ fruits with different cracking degrees were randomly collected. The degree of cracking was divided into four grades: slight cracking, mild cracking, moderate cracking, and severe cracking (Fig. 6). According to the statistical results, regardless of the degree of cracking, none of the jujube fruits contained normally developed seeds, and their embryo abortion rate was $100 \%$. The embryo abortion degree of cracking fruits was significantly higher than that of jujube fruits that did not crack. All the fruits with seed kernels observed during the early stage did not crack. However, whether there is a certain relationship between embryo abortion and the cracking degree of jujube fruits needs further exploration.

For jujube fruits that did not crack, the fertility rate of embryos was $3.16 \%$ and the embryo abortion rate was $96.84 \%$. Based on the fertility grades of jujube fruits determined by another study (Wang, 2004), the fertility rate of $Z$. jujuba Mill. 'Zhongqiusucui' was less than $5 \%$; therefore, it was a highly abortive cultivar.

Correlation analysis. A correlation analysis of all fruit characteristics was performed (Table 7). The results indicated that there were different degrees of correlation among the embryo abortion rate and six fruit traits. The embryo abortion rate was negatively correlated with the fruit vertical length, cross diameter, and weight, and the correlation coefficients were all greater than 0.700 . There were significant positive correlations among the embryo 
Table 7. Correlation coefficient of fruit traits and embryo abortion rate.

\begin{tabular}{|c|c|c|c|c|c|c|c|}
\hline Fruit traits & $\begin{array}{c}\text { Fruit vertical } \\
\text { length }\end{array}$ & $\begin{array}{c}\text { Fruit cross } \\
\text { diam }\end{array}$ & Fruit wt & $\begin{array}{c}\text { Fruit shape } \\
\text { index }\end{array}$ & $\begin{array}{c}\text { Degree of } \\
\text { lignification }\end{array}$ & $\begin{array}{c}\text { Degree of } \\
\text { cracking }\end{array}$ & $\begin{array}{c}\text { Embryo } \\
\text { abortion rate }\end{array}$ \\
\hline Fruit vertical length & 1 & & & & & & \\
\hline Fruit cross diameter & $0.933 * *$ & 1 & & & & & \\
\hline Fruit weight & $0.933 * *$ & $0.938 * *$ & 1 & & & & \\
\hline Fruit shape index & $-0.206 * *$ & $-0.331 * *$ & $-0.255^{* *}$ & 1 & & & \\
\hline Degree of lignification & $0.082 *$ & 0.025 & $0.084 *$ & $0.078^{*}$ & 1 & & \\
\hline Degree of cracking & $0.569 * *$ & $0.639 * *$ & $0.672 * *$ & $-0.562 * *$ & -0.06 & 1 & \\
\hline Embryo abortion rate & $-0.819 * *$ & $-0.776^{* *}$ & $-0.829 * *$ & $0.183 * *$ & $0.182 * *$ & $0.678 * *$ & 1 \\
\hline
\end{tabular}

**Represents significant correlation at $P<0.01$. *Represents significant correlation at $P<0.05$.

abortion rate and fruit shape index, degree of lignification, and degree of cracking. The correlation coefficient between the embryo abortion rate and fruit cracking degree was 0.678.

\section{Discussion}

The embryo abortion rate of jujube fruits was closely related to the fruit size. A higher kernel content rate was found mainly for large fruit and medium fruits in different batches and on two types of jujube-bearing shoots, and the average embryo abortion rate of large fruit was lower than that of small fruits. Liang (2013) studied kernel content rates of different jujube cultivars and divided them into three embryo abortion types: complete abortion type, abortion type of medium and small fruits, and abortion type of small fruits. Large fruits had a higher kernel content rate and medium and small fruits had no kernels. The research results of Wang (2004) and $\mathrm{Li}$ et al. (2016) regarding abortion degrees of different jujube cultivars (such as Ziziphus jujuba Mill. 'Lizao', Ziziphus jujuba Mill. 'Dongzao', Ziziphus jujuba Mill. 'Lengbaiyu', Ziziphus jujuba Mill. 'Liuyuexian', and Ziziphus jujuba Mill. 'Hupingzao') also showed that the kernel content rate of large fruits was higher. This might have occurred because a large number of young fruits fell off during the physiological fruit-falling period, resulting in changes in the population used to calculate the embryo abortion rate; however, after a large number of young fruits fell off, the nutritional competition was reduced so that the nutritional level of the young fruits that did not fall off was relatively high and the fruits developed better. $\mathrm{Li}$ et al. (2016) found that the embryo abortion rate of abnormal fruits (yellow color and about to fall off) was higher than that of normal fruits of several jujube cultivars, and they speculated that embryo abortion was an important factor leading to physiological fruit drop.

There were no significant differences in the embryo abortion rates of the first and second batches, but the embryo abortion degree of fruits in the third batch was the highest. This might have occurred because the jujube fruit-bearing time of the third batch was late, and the nutrition level of the tree body decreased to some extent, which affected fruit development to a certain extent, thus impacting the kernel content. Relevant research showed that the percentage of the esculent part of the fruit and total soluble sugar content of the third batch were low (Hu et al.,
2017). However, the smoothest skin and fewest dots on the surface of jujube fruits were observed on the third batch.

The embryo abortion rates of jujube fruits on the two types of bearing shoots were different. The embryo abortion degree of jujube fruits on lignified bearing shoots was higher than that of fruits on nonlignified bearing shoots, and the probability of double kernels was higher for fruits on nonlignified bearing shoots than for fruits on lignified bearing shoots. According to relevant studies, the water and nutrient transport tissues of lignified bearing branches were more developed than those of non-lignified bearing shoots; therefore, the ability of nutrient transport and accumulation of lignified bearing branches were stronger than those of nonlignified bearing branches. Moreover, the lignified bearing branches had a higher photosynthate accumulation capacity (Wang and Yan, 2014; Wang et al., 2014, 2017; Yan et al., 2013). However, the embryo abortion rate of jujube fruit on lignified bearing shoots was higher than that of fruit on nonlignified bearing shoots. The reasons for this need further exploration.

The embryo abortion rates of jujube fruits with smaller and larger fruit shape index values were lower, and the embryo abortion rate of cylindrical fruits (fruit shape index range, 1.30-1.60) was higher. The embryo abortion rates of globose, oblong globose, and long cylindrical fruits were lower and that of cylindrical fruit. Liang (2013) studied the kernel content rate of different jujube cultivars and found that the distribution of the fruit shape index values of different embryo abortion types was different. For jujube cultivars with abortive small or medium fruits, the fruit shape index values of abortive fruits mainly ranged from 1.356 to $1.60,1.34$ to 1.51 , and 1.38 to 1.57 (Liang, 2013); these results were similar to those of this study. Therefore, the fruit shape was highly correlated with the kernel content rate. Accordingly, the shape of jujube fruits should be considered when investigating the embryo abortion rates in the future.

The results showed that there were significant differences in embryo abortion degrees of cracking and normal jujube fruits. The rate of embryo abortion of cracking fruits was $100 \%$, which was significantly higher than that of noncracking fruits; moreover, there was a significant positive correlation between the embryo abortion rate and degree of cracking. Cao et al. (2014) found that the seed abortion rate of the easily cracking cultivar Ziziphus jujuba Mill. 'Junzao' was significantly higher than that of
Ziziphus jujuba Mill. 'Yuanlingzao' which is a noncracking jujube cultivar. Moreover, the abscisic acid (ABA) content in the pulp and seeds of $Z$. jujuba Mill. 'Junzao' was significantly lower than that of $Z$. jujuba Mill. 'Yuanlingzao'. The reasons for this might be that the accumulation of ABA induced the synthesis of various proteins during the middle and late stages of embryo development, promoted the normal development of seeds, and effectively reduced the seed abortion rate (Song et al., 1997). Related studies showed that ABA accumulated rapidly in normal seeds at the later stage of jujube fruit development (Wang et al., 2008). Therefore, it was speculated that the lack of ABA content in seeds might be one of the factors affecting the occurrence of fruit cracking. Fruit cracking is a widespread physiological disease of jujube that has hindered the development of the jujube industry in China for a long time and has caused considerable economic losses for fruit growers. Allocation with different pollinizers can reduce the embryo abortion rate to control fruit cracking, which will have a certain significance for the guidance and realization of green production.

\section{Literature Cited}

Cao, Y.B., C.J. Li, F. Sun, and L.Y. Zhang. 2014. Comparison of the endogenous hormones content and the activities of enzymes related to cell-wall metabolism between jujube cultivars susceptible and resistant to fruit cracking. Acta Hort. Sinica 41(1):139-148 (in Chinese), doi: 16420/j.issn.0513-353x.2014.01.017.

Gao, Q.H., C.S. Wu, and M. Wang. 2013. The jujube (Ziziphus jujuba Mill.) fruit: A review of current knowledge of fruit composition and health benefits. J. Agr. Food Chem. 61(14): 3351-3363, doi: 10.1021/jf4007032.

Gao, Q.L., Z.L. Wang, M.J. Lin, and J.Y. Wang. 2019. Study on seed content and fertility of different jujube varieties. Xinjiang Agr. Sci 56(12):2275-2281 (in Chinese), doi: 10.048/ j.issn.1001-4330.2019.12.013.

$\mathrm{Hu}$, Q. 2017. Comparison of the results of multiharvesting of southern fresh jujube. Thesis for M.S., Central South University of Forestry and Technology, Changsha (in Chinese), doi: 10.7666/d.Y3269091.

Hu, Q., S. Wang, Z.Q. Zhang, F.X. Shao, and Y. Wu. 2017. Comparison in quality of southern fresh Zizyphus jujube in different batches. J. Central South Univ. Fore. Technol. 37(11):63-68 (in Chinese), doi: 10.14067/j.cnki.1673-923x.2017.11.011

Li, D.K., X.F. Xue, Y.K. Wang, A.L. Zhao, H.Y. Ren, C.L. Sui, M.J. Shi, X.H. Du, and Q. Liang. 2016. Observation of embryo 
development an abortion in Chinese jujube (Ziziphus jujuba Mill.). Acta Agr. Bor-Occid. Sin. 25(9):1379-1385 (in Chinese), doi: 10.7606/j.issn.1004-1389.2016.09.015.

Liang, C.L. 2013. A Survey on seed abortion of Ziziphus jujuba Mill. J. Liaoning Agr. College 15(6):14-16 (in Chinese), doi: CNKI:SUN:LNNJ.0.2013-06-007.

Liu, L., J.R. Wang, M.J. Liu, and J.Y. Zhao. 2006. Pollen number and its germination rate of different Chinese jujube cultivars. J. Plant Genet. Resour. 7(3):338-341 (in Chinese), doi: 10.13430/j.cnki.jpgr.2006.03.017.

Liu, M.J., J.R. Wang, P. Liu, J. Zhao, Z.H. Zhao, L. Dai, X.S. Li, and Z.G. Liu. 2015. Historical achievements and frontier advances in the production and research of Chinese jujube (Ziziphus juju$b a)$ in China. Acta Hort. Sinica 42(9):1683-1698, doi: 10.16420/j.issn.0513-353x.2015-0538.

Liu, M.J., J.R. Wang, P. Liu, M.J. Lin, J. Xiao, Z.G. Liu, and X.C. Sun. 2014. Design and practice of emasculation-free cross breeding in Chinese jujube. Acta Hort. Sinica 41(7):1495-1502 (in Chinese), doi: 10.16420/j.issn.0513-353x.2014.07.025.

Liu, M.J. and M. Wang. 2009. Germplasm resources of Chinese jujube. China Forestry Publishing House, Beijing, China (in Chinese).

Qu, Z.Z. and Y.H. Wang. 1993. China fruit's monograph-Chinese jujube volume. China Agriculture Publishing, Beijing, China (in Chinese).
Shao, F.X., S. Wang, Z.M. Liu, and R.Y. Hong. 2020. Pollination fertilization and embryo development in southern China fresh-eating jujube. HortScience 55(8):1315-1322, doi: 10.21273/HORTSC15144-20.

Song, S.Q., Y.X. Duan, and J.R. Fu. 1997. Regulation of ABA on seed development. Seed (5):36-42 (in Chinese), doi: 10.16590/ j.cnki.1001-4705.1997.05.039.

Wang, J.R. 2004. Studies on male sterility and embryo abortion of Chinese jujube (Ziziphus jujuba Mill.). Thesis for PhD, Hebei Agricultural University (in Chinese), doi: 10.7666/d.y612430.

Wang, J.R., H.Y. Liang, and M.J. Liu. 2008. The relationship between endogenous hormone changes and embryo abortion during fruit development of Chinese jujube male sterile germplasm. J. Plant Genet. Resour. 9(3):367-371 (in Chinese), doi: 10.13430/ j.cnki.jpgr.2008.03.022.

Wang, S. and C. Yan. 2014. Comparison of the accumulation ability of photosynthetic product between two types of bearing shoots of southern China fresh-eat jujube. Sci. Silva. Sin. 34(12):35-39 (in Chinese), doi: 10.11707/ j.1001-7488.20140612.

Wang, S., C. Yan, and B.L. Deng. 2014. Comparation study of transporting ability in two kinds of bearing branches in southern China fresheat jujube. J. Central South Univ. Fore.
Technol. 34(12):35-39 (in Chinese), doi: 10.14067/j.cnki.1673-923x.2014.12.006.

Wang, S., C. Yan, and F.X. Shao. 2017. Comparation study of blooming and fruiting ability in two types of bearing shoot in southern China fresh-eat jujube. J. Central South Univ. Fore. Technol. 37(3):9-16 (in Chinese), doi: 10.14067/j.cnki.1673-923x.2017.03.002.

Wang S., X.B. Xie, Q.P. Zhong, Z.Y. Gu, J.Q. Zeng, and J.X. Zeng. 2009. A new Zizyphus jujube cultivar 'Zhongqiusucui'. Acta Hort. Sinica (5):771-781 (in Chinese), doi: 10.16420/ j.issn.0513-353x.2009.05.024.

Wang, Y. 2008. Studies on pollination biology of jujube. Thesis for M.S., Hebei Agricultural University (in Chinese), doi: 10.7666/d.y1306836.

Yan, C., S. Wang, and F.X. Shao. 2013. Comparison of leaf photosynthetic efficiency of lignified and non-lignified bearing branches in southern fresh-eat jujube. Non-wood Forest Res. 31(2):113-117 (in Chinese), doi: 10.14067/j.cnki.1003-8981.2013.02.016.

Zhang X.Y., S.Q. Peng, and Z.H. Guo. 2004. Studies on the pollination, fertilization and embryo development of Chinese Jujube (Ziziphus juju$b a$ ). Sci. Silva. Sin. 40(5):210-213 (in Chinese), doi: $10.11707 / \mathrm{j} .1001-7488.20040535$.

Zhou, J.H. 1999. Unseasonable flowering and bearing phenomenon of fruit trees. Acta Agr. Jiangxi (4):64-68 (in Chinese), doi: 10.19386/ j.cnki.jxnyxb.1999.04.013. 